\title{
A world sea safety system using second generation WIG
}

\author{
E. A. Aframeev ${ }^{1} \&$ Y. Yoshida ${ }^{2}$ \\ ${ }^{1}$ Organizing Committee of IGS SSS, Russian Federation \\ ${ }^{2}$ Technical University of Varna, Japan
}

\begin{abstract}
The authors present an effective rescue system in the future for a ship in distress etc within second generation WIG's cruising radius $3000-4000 \mathrm{~km}$, using international satellite communications. 50 WIGs will be arranged on 12-13 bases for global rescue works. Each base has 3 or 4 WIGs. One or two WIGs start from a base after picking up signals for help. The WIG, having 750 ton in weight, $95 \mathrm{~m} \times 85 \mathrm{~m}$ in length and width, 400-450 km/hour in cruising speed, 70 ton in payload, and appendages such as 1 helicopter, 3 motorboats, 1 tugboat for oil barrage, 10 rescue rafts, 1 bathyscaphe, is designed as a large catamaran. The design is based on many experiment and field test data up to 550 ton in weight called "KM type" on Russian Federation's national project. The WIG will take off and land on up to 3.5-4.0 $\mathrm{m}$ in wave height (hump to hollow), which enable us to use it about $95 \%$ of a year time on open sea. The system will work for not only rescues but also police activities. The WIG is an advanced flying boat that flies ultralow altitude utilizing wing-in-ground effect, which is also called "ekranoplane".

Keywords: WIG, ekranoplane, flying boat, wing-in-ground effect, global rescue system, sea disaster.
\end{abstract}

\section{Introduction}

First the system component together with its acronym is discussed as follows: 


\subsection{Wing-in-ground-effect and WIG}

The system uses 50 craft which cruise over water keeping ultralow altitude. Wing-in-ground effect enables them to cruise at an ultralow altitude. The effect is as follows: Ground gives more pressure to wings of a plane cruising with constant speed at an ultralow altitude. The pressure-increase level on a ground point under wings is directly proportional to the plane's weight and inversely proportional to the square of the altitude. WIG is the abbreviation for wing-inground effect plane, which is also called ekranoplane.

\subsection{Ekranoplane}

It is no exaggeration to say that the Russian Federation's WIG R\&D group has the mainstream of WIG R\&D. They have not only many research works but also quite a lot of data for design in the field of WIG. The design of heavy WIG has been discussed as references [1] and [2] since around the turn of the century. They have named WIG "Ekranoplane" since the start of the R\&D. Then authors use "Ekranoplane" in sections 3 and 4. "WIG" is getting popular through many names such as "Ekranoplane", "Ekranoplan" [3], "WIG effect vehicle" [3] "Wing-in-surface effect craft" [4].

\subsection{Rescue circumstances}

A loss of \$1-2 billion a year nowadays comes out of sea disasters, which is counted up against only ship and material losses. Ships carrying oil or dangerous material can cause ecology to damage at a disaster. Emergency helps from a remote accident scene often trouble rescue agencies with carrying necessary persons and tools to the scene as soon as possible. Existent aircrafts such as airplanes, helicopters, flying boats cannot carry heavy things. Weather sets a limit to their flights. No integrated marine security system in the world is designed at present.

Rescue works in an accident scene need rescuers and tools such as helicopters, boats, bathyscaphes. A carrier to the scene requires not only carrying capacity for them but also excellent performance: high speed, cruising long distance, high seaworthiness and high quality in both takeoff and landing.

\section{The present rescue system}

The authors present such effective system as to satisfy the above items for rescuing crew and passengers from a damaged ship etc within a radius of 3000 $4000 \mathrm{~km}$ from a base with the speed $400-450 \mathrm{~km} /$ hour. International cooperation will bring great effect to this system [1, 5-7].

The WIG as the system component can do many kinds of works in the field. The more kinds of works are needed, the heavier weight a WIG gets. The present WIG is the heaviest one. We want to find creation-possibility of such a WIG. 
The second generation WIG model's test data, together with the R\&D record of the first generation WIGs, give us strong creation-possibility of the second generation WIGs, which is mentioned in the next sections 3 through 6 .

\section{First generation WIG project}

The authors present the R\&D record of the first generation WIGs in chronological order, in order to clarify creation-possibility of the second generation WIGs. The first generation WIG project seems to be the second generation WIG's model test using the models on a scale of about 1 to 2 .

All first generation WIGs have been built as mono-hull plane (see Fig. 1-7). These R\&D began in the latter half of the twentieth century.

\subsection{Experimental model "KM"}

It was created in 1966, which has 550 ton in weight and $400 \mathrm{~km} /$ hour in speed (see Fig. 1).

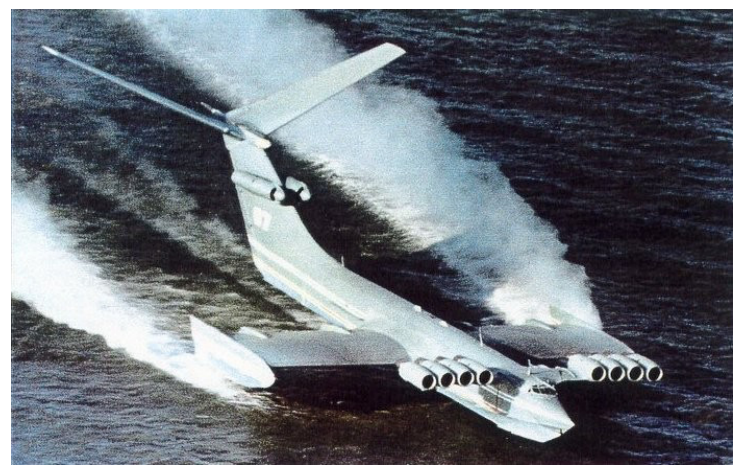

Figure 1: $\quad$ Experimental model "KM".

\subsection{Transport and landing ekranoplane "Orlenok"}

It was created in the $1980 \mathrm{~s}$, which has 140 ton in weight and $400 \mathrm{~km} / \mathrm{hour}$ in speed (see Fig. 2).

\subsection{Rocket ekranoplane "Lun"}

It was created in $1980 \mathrm{~s}$, which has 350 ton in weight and $500 \mathrm{~km} /$ hour in speed (see Fig. 3).

\subsection{Emergency-rescue ekranoplane "Spasatel"}

It is a failure-rescue ekranoplane as the first emergency-rescue ekranoplane in the world. After long break because of financial lack, re-equipment of "Lun" gives us "Spasatel" (see Fig. 4). 


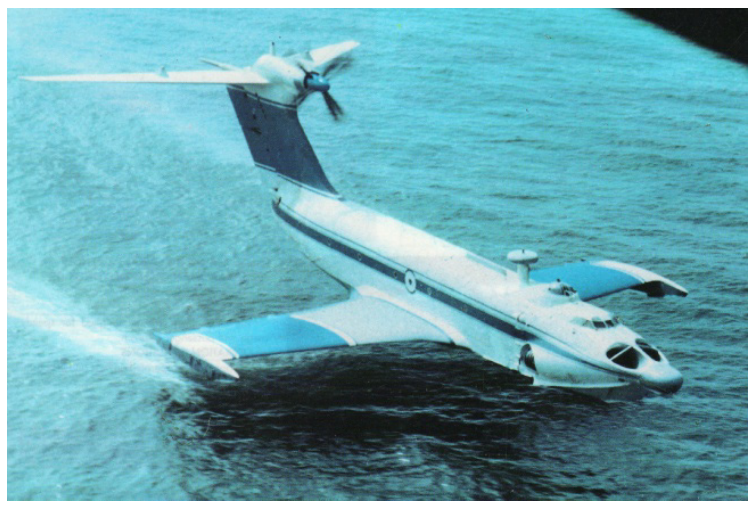

Figure 2: Transport and landing ekranoplane "Orlenok".

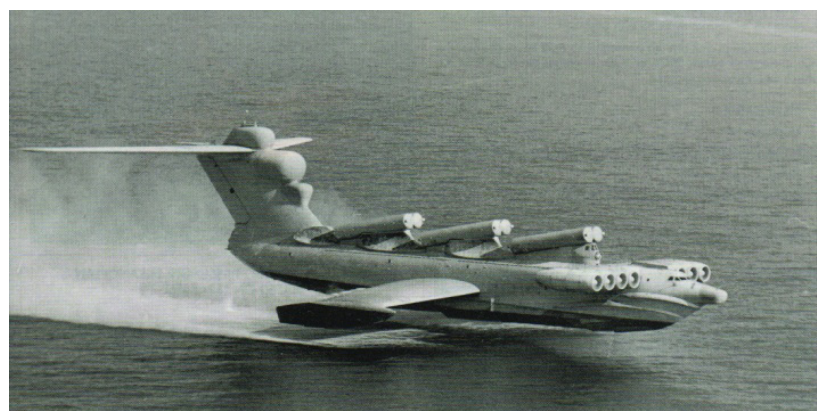

Figure 3: Rocket ekranoplane "Lun".

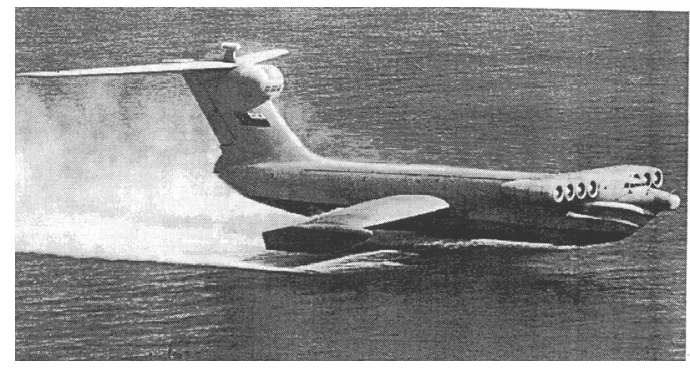

Figure 4: $\quad$ Failure-rescue ekranoplane "Spasatel".

\subsection{Spasatel's variant}

The failure-rescue ekranoplane shown in Fig. 5 is the Spasatel's variant. It has a bathyscaphe on the hull. 


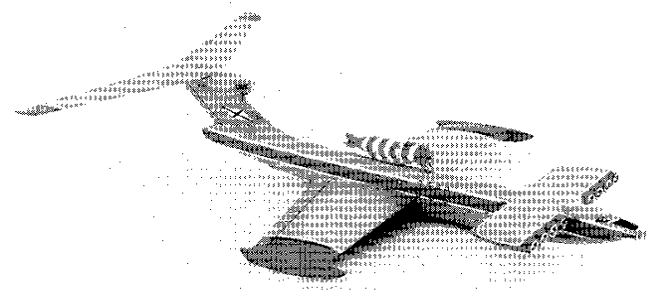

Figure 5: Spasatel's variant.

\subsection{Saving complex "Mrija-Orlenok"}

It has a plane on the hull (see Fig. 6). Studying "Mrija-Orlenok" developed into the study on launching a space shuttle from an ekranoplane [8].

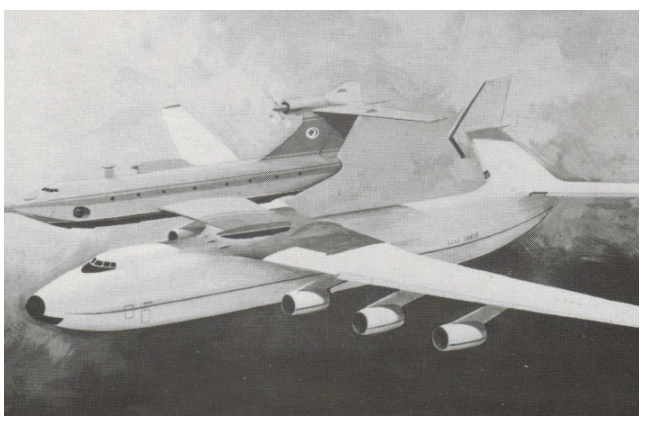

Figure 6: $\quad$ Saving complex "Mrija-Orlenok”.

\subsection{Natural rescue-experiment on "Lun"}

A number of field tests shown in Fig. 7 has been executed.

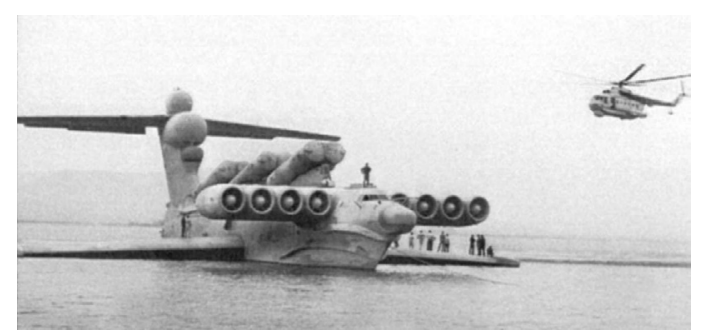

Figure 7: Rescue experiment on "Lun".

\subsection{Results}

The first generation WIG project shows the following imperfections: 
1. Less performance at takeoff and landing;

2. Short range under low speed;

3. Shortage of both inner space and carrying capacity;

4. Carrying no helicopter;

5. Difficulty of using bathyscaphe.

And this project shows creation-possibility of larger size WIGs.

The second generation WIG project succeeds to both larger size and improving the first generation WIG's imperfection, which is mentioned further in the next sections 4 and 5 .

\section{Second generation WIG project}

\subsection{Research work "Vzlet"}

The second generation WIG project start as the research work called "Vzlet".

Several research and design organizations for shipbuilding and aviation in the Soviet Union researched on creation-possibility of an ekranoplane carrying combat aircrafts in early 1970.

\subsection{Vzlet 2}

Vzlet 2 began in 1977. Dr. Eduard A. Aframeev, chief of department Krylov Shipbuilding Research Institute in St. Petersburg, had been selected as their leader, when Vzlet 2 began.

He is the first author of this report. He not only controlled the national project but also researched his own themes "Large size ship cruising above water", "Advanced flying boat" etc.

The results of the above mentioned research are as follows:

1. Military use of ekranoplanes is inexpedient;

2. A large size catamaran is the optimum hull for each second generation WIG;

3. Second generation ekranoplanes should be used for special tasks that cannot be solved by other means such as long range rescue on sea.

\subsection{Second generation WIG's hull}

The authors have adapted catamaran from mono-hull as the second generation WIG's hull. More designers expecting more stability prefer catamaran to monohull from around the turn of the century [9] (see Fig.8-10).

\section{Second generation WIG}

The second generation WIG (see Figs 8-10) is designed as a large catamaran having the following main items: 
1. Weight is 750 ton;

2. Principal dimensions are $95 \mathrm{~m}$ in length, $85 \mathrm{~m}$ in width and $17 \mathrm{~m}$ in height;

3. Speeds are $400-450 \mathrm{~km} /$ hour in flying over water and $30-35 \mathrm{~km} /$ hour in low speed as a ship;

4. Cruising ranges are $6500 \mathrm{~km}$ in flying and $9500 \mathrm{~km}$ in low speed as a ship (A mission range is $3000-4000 \mathrm{~km}$ );

5. Clearing wave height (hump to hollow) against takeoff and landing is 3.5$4.0 \mathrm{~m}$;

6. Payload is 70 ton;

7. Effective wing area is $1200 \mathrm{~m}^{2}$;

8. Equipments are 1 helicopter, 3 motorboats, 1 tugboat for oil barrage, 10 rescue rafts and 1 bathyscaphe.

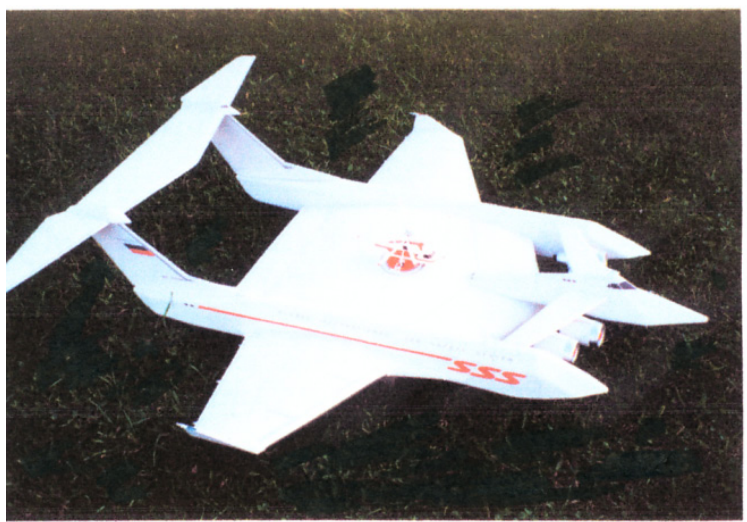

Figure 8: $\quad$ Second generation WIG.

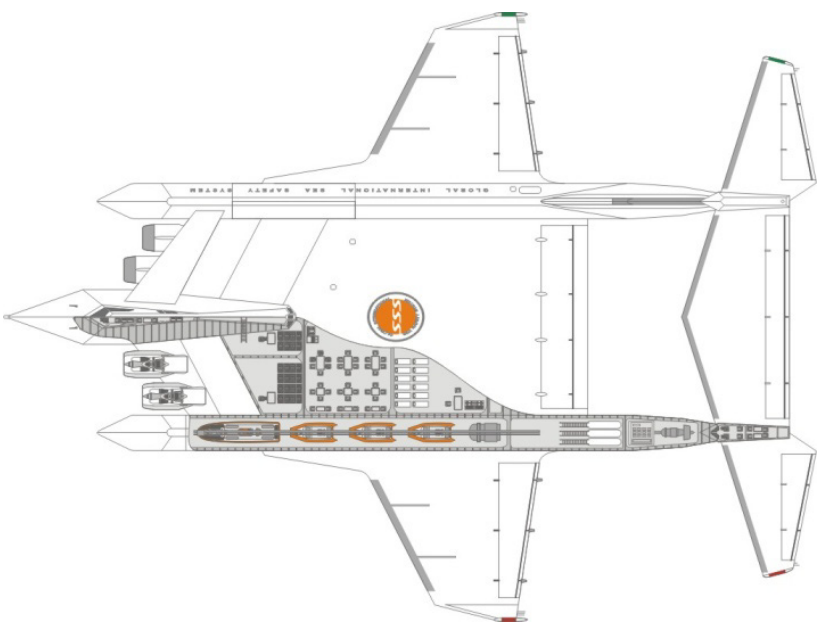

Figure 9: $\quad$ Plane figure. 


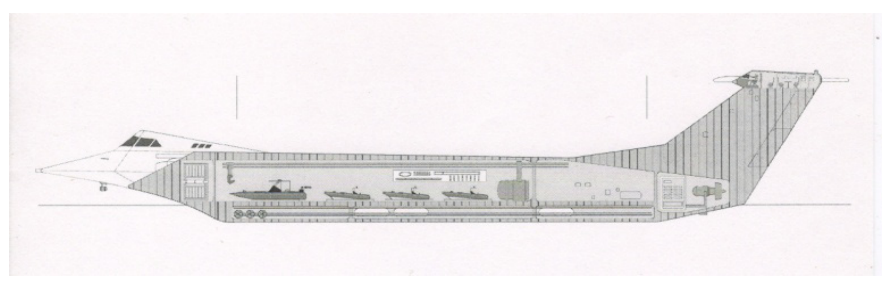

Figure 10: Cross section.

\section{Model test for second generation WIG}

The model test items on the second generation WIG and the improvements are as follows:

\subsection{Model test items on the second generation WIG [5]}

\subsubsection{Open harbour area test}

The self-propulsion tests at each ratio of propulsive force to hull weight were done on both still and roughness water. Forces into hull at takeoff and landing and configuration of jet stream have been clarified.

\subsubsection{Dry basin test}

The motion stability tests were done above both flat and irregular surface of the racetrack. Aerodynamic forces into hull have been clarified.

\subsubsection{Catapult installation}

Launch tests from catapults on the model which is running above small or large circular racetrack were done. The optimum position of the centre of gravity and the pitch angle of the model have been clarified for longitudinal and transversal motion stability.

\subsubsection{Ship research basin test}

Several hull forms were tested to study floating motion and conditions at takeoff and landing. Hydrodynamic characteristics and propulsive coefficient at each jet stream condition have been clarified.

\subsubsection{Wind tunnel test}

Several hull forms were tested above a fixed or moving screen in the tunnel to study aerodynamic characteristics as altitudes. The optimum hull form, interaction between hull elements, vortex performance and control efficiency of the model have been clarified.

\subsubsection{Jet stream test on bench}

Several jet stream conditions on the model were tested at each location of engine to obtain fundamental data for cruising above water and land surface. Forces and moments into hull, main structural members of hull and ratio of propulsive force to hull weight have been clarified. 


\subsection{Improvements}

The model test results of the second generation WIG show more desirable performance than that of the first generation WIG. All first generation WIGs have been made as mono-hull (see Fig.1-7). The improvements are as follows:

1. $40-50 \%$ increase in lift-drag ratio on both still and roughness water compared with the first generation WIG's one;

2. $50 \%$ increase in lift-drag ratio above water compared with the first first generation's one;

3. Better performance on intensive conditions such as takeoff and landing, flying above obstacles;

4. Better payload;

5. Better mileage.

\section{Operations}

The following operations will be executed by using the second generation WIG:

1. Rescuing crew and passengers from a damaged craft such as aircraft, ship, floating excavator, submarine;

2. Carrying rescuers, rescue tools, and materials to the accident scene;

3. Initial prevention work against such a large scale of oil-float as damaging ecology;

4. Watching ecology;

5. Protection for conservation area;

6. Police activity;

7. Supporting ocean R\&D.

The low speed items in the section 5 may be necessary for some operations.

A global sea safety system in case of rescue operation is presented in the next section.

\section{Global sea safety system}

Each mission range $3000-4000 \mathrm{~km}$ apart from the nearest base is shown as Fig.11. 50 WIGs will be arranged on 12 or 13 bases for rescue works. Each base has 3 or 4 WIGs.

One or two WIGs start from a base to an accident scene after picking up signals for help. The necessary works at the scene will be started in shorter time because of WIG's characteristics.

The communication of the system will be done by international satellite communications such as COSPAS-SARSAT, INMARSAT, GLONASS.

International cooperation will bring great effect to the system.

The authors have called this "IGS SSS" that is the abbreviation for International Global System Sea Safety System [5-7]. 


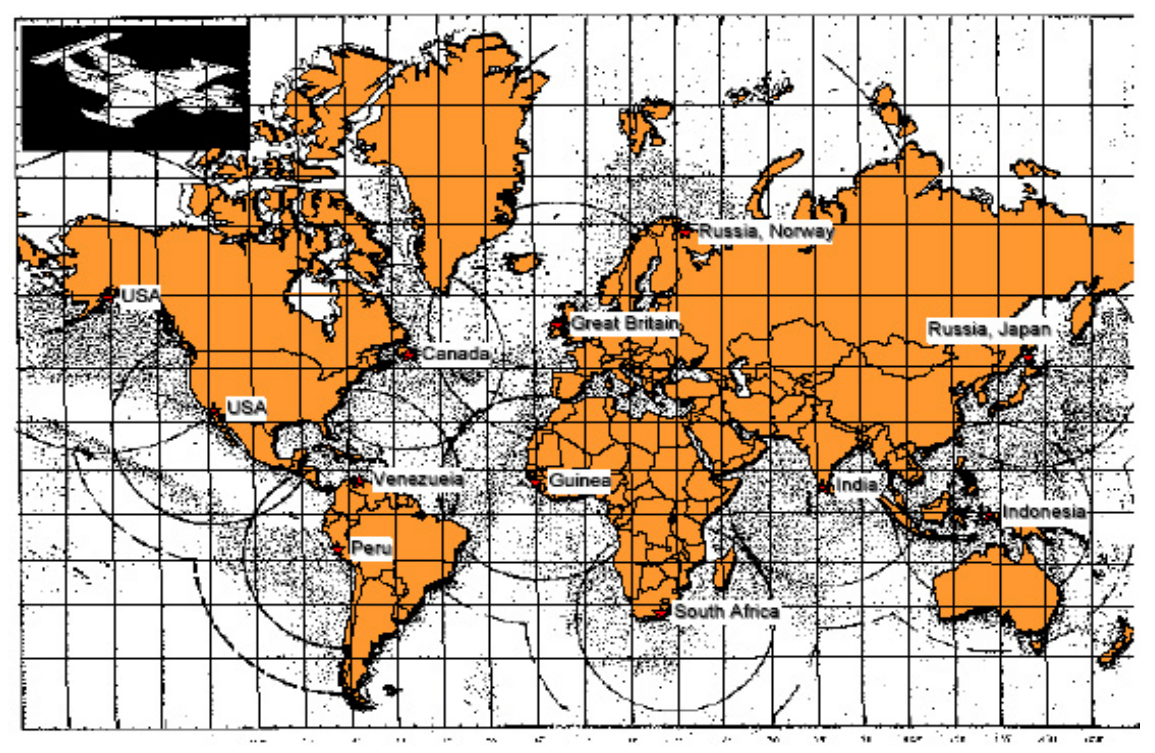

Figure 11: Mission ration range of a base.

\section{Conclusions}

A global sea safety system in the future is presented, which uses 50 WIGs under international satellite communications. As the system component, a second generation WIG can do several kinds of works at an accident scene using its equipment such as 1 helicopter, 3 motorboats, 1 tugboat for oil barrage, 10 rescue rafts, 1 bathyscaphe. Three or four WIGs can work within a radius of $3000-4000 \mathrm{~km}$ from a base with the speed $400-450 \mathrm{~km} /$ hour. 12 or 13 bases are arranged on the world.

This system will be used for not only rescue but also police activity etc.

The second generation WIG's model test data, together with the R\&D record of the first generation WIGs, give us strong creation-possibility of the second generation WIGs.

\section{References}

[1] Aframeev, E.A. and Volkov, L.D., Projection of a heavy wing-in-ground effect craft for a high-speed segment of a sea safety system. Proc. of the $2^{\text {nd }}$ Int. Conf. NSN'2001 (St. Petersburg, Russian Federation), pp. 344-351, 2001.

[2] Aframeev, E.A., Conceptual bases of WIG craft building: ideas, reality and outlooks. Proc. of the NATO RTO Meeting No.15 Fluid Dynamics Problems of Vehicles Operating Near or in the Air-Sea Interface (Amsterdam, The Netherlands), pp. 22-1 -22-17, 1998. 
[3] Alexandrov, G.V., Gryazin, V.Y. and Strelkov, V.V., Control automation of passenger ekranoplans, Proc. of the $3^{\text {rd }}$ Int. Euro Conf. On HighPerformance Marine Vehicles HIPER'02 (Bergen, Norway), pp. 13-21, 2002.

[4] Akimoto., H, Matsuzaki, Y., Ogawa, Y., Takezume, T. and Kubo, S., Wind tunnel measurements of 6-component forces and moments acting on a model of new wing-in-surface effect craft of all-wing type for 8 passengers, Proc. of the $3^{\text {rd }}$ Int. Euro Conf. On High-Performance Marine Vehicles HIPER'02 (Bergen, Norway), pp. 3 -12, 2002.

[5] Aframeev, E.A., Yoshida, Y. and Kiselev, V.M., International global system-sea safety system (IGS SSS) -System of sea safety of the future. Proc. of the $9^{\text {th }}$ Int. Symp. On Marine Engineering ISME KOBE 2011 (Kobe, Japan), pp. 1-6 of D8-1, 2011.

[6] Aframeev, E.A., A global international sea safety system based on heavyclass wing-in-ground effect crafts. Journal of Shipbuilding (St. Petersburg, Russian Federation), 9(737), pp. 11-13, 2001.

[7] Aframeev, E.A. and Savichenko, N.P., XXI Century's ekranoplane's system-SSS and WSL. Proc. of the Int. Conf. GEM 2007 (St. Petersburg, Russian Federation), pp. 11-13, 2001.

[8] Aframeev, E.A., Nebylov, A.V., Savichenko, N.P., Tomita, N and Yoshida, Y., Study of a sea launch concept of aerospace shuttle with heavy ekranoplane as takeoff and landing assist, Proc. of the Int. Symp. On Marine Engineering ISME TOKYO 2000 (Tokyo, Japan), pp. 745-750 of Vol.2, 2000.

[9] Yoshida, Y., The Report on the $3^{\text {rd }}$ International Euro Conference on HighPerformance Marine Vehicles HIPER'02 (Bergen, Norway), Bulletin of the Society of Naval Architects of Japan (883), pp. 140-144, 2005. 